
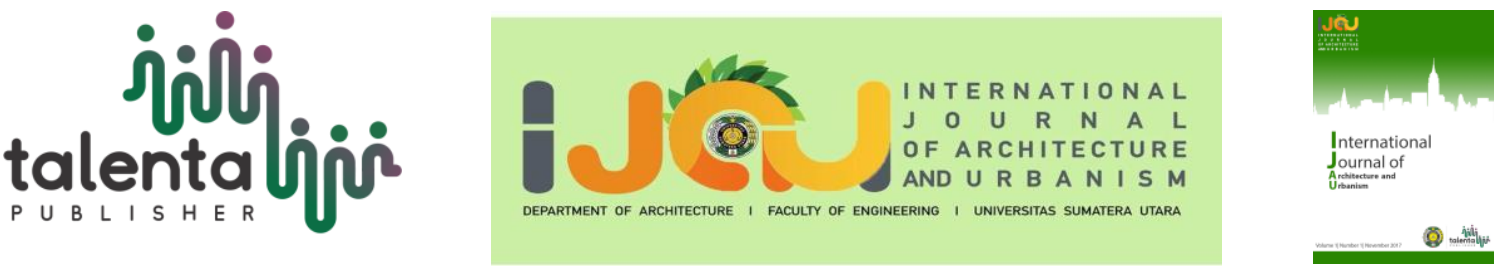

\title{
Studies of Reasonable Magnitude of Additional Force And Effect of Reinforcement In Reinforcing of Steel Truss Structure
}

\author{
Yong Il Song ${ }^{1^{*},}$ Il Ju Ri \\ ${ }^{1}$ Pyongyang University of Architecture, DPRK
}

\begin{abstract}
When the truss structure is reinforced in operating state the additional force is given to it.We propose the method for determining the reasonable magnitude of additional force to reduce the internal force by minimum condition strain energy of truss.
\end{abstract}

Keyword: reinforcing of steel truss structure, steel truss, reinforcing

Received 3 October 2021 |Revised 5 November 2021 | Accepted 7 November 2021

\section{Introduction}

In case of reinforce the damaged section of construction in operation or load up the bigger load than the planned load; it should be in need of lighten the load that construction is suffering. In generally, in the technological construction methods it is used the method that reinforce the construction by lightening the appropriate amount of operation load or total load and then load up [1] [2]. But these methods need many materials, labor and construction term because of before reinforcement they should be lighten the load of construction and then after reinforcement they should be load up again. If the opposite directional force to gravity reacts on the mechanical system received the action of external force by gravity, internal force of the initial system would be decreased [3]. So applying the principle that internal force is decided by the total sum of external forces, the purpose of this research is to react some additional external force that the total sum of external forces equals or approximates to zero. In that case, the reinforcing effect of structure colud be enhanced to the maximum.

Therefore the problems to solve in this paper are as follows.

Where we should activate the additional external force in structure?

*Corresponding author at:Taedonggang Dong, Taedonggang District, Pyongyang, DPRK

E-mail address: shypinguo202126@yeah.net 
How is the strength of additional external force to activate?

This is an inverse problem that decide external force from informations of the internal forces of structure. But because of the inverse problem assured of the corresponding relation of solutions, here we would like to discuss the method to convert this problem into some optimum problem. That method appropriates to other types of structure such as beam. For convenience of considering the problem it is assumed that the movements of truss structure are expressed by the basic equation of finite element method.

\section{Setting the problem for determination of additional external force in truss structure}

In considered truss the place to apply the additional force is given and assumed that the number of additional force is joint load that reacts to two joints without limitation of generality [4]. If the additional external force reacts to the joint that isn't suffering operational load, we suggest that $\mathbf{P}$ is operational load vector (this vector is zero to the joint that isn't suffering load like as the finite element method. But it has the dimension such as numer of joints except the joints to activate additional external force.), and $\mathbf{P}_{\mathrm{II}}$ is additional external force.

Then in case additional external force would be reacted, the stiffness equation of considering truss is as follow (Figure 1 and Figure 3).

$$
\left[\begin{array}{ll}
\mathbf{K}_{\mathrm{II}} & \mathbf{K}_{\mathrm{III}} \\
\mathbf{K}_{\mathrm{III}} & \mathbf{K}_{\mathrm{III}}
\end{array}\right]\left\{\begin{array}{l}
\mathbf{u} \\
\mathbf{u}_{\mathrm{II}}
\end{array}\right\}=\left\{\begin{array}{l}
\mathbf{P}_{\mathrm{I}} \\
\mathbf{P}_{\mathrm{II}}
\end{array}\right\}
$$

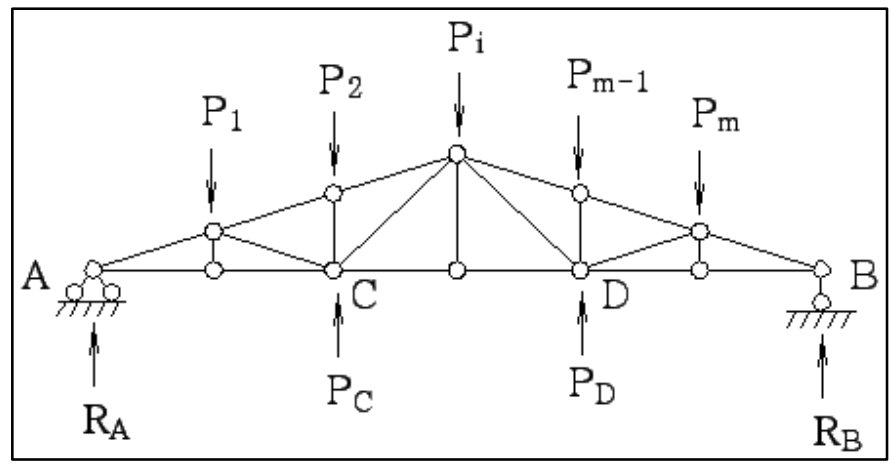

Figure 1. Diagram for calculating the strength of additional external force when the steel truss is reinforced.

Here appendix “II" , “I ” mean values of sectional structures including the joints activated additional external force and remant joints.

That is, $\mathbf{u}_{\mathrm{II}}, \mathbf{P}_{\mathrm{II}}$ mean displacement and external force vector corresponding to the joins activated additional forces [5], and $\mathbf{u}_{\mathrm{I}}, \mathbf{P}_{\mathrm{I}}$ mean displacement and external force vector 
corresponding to the remant joints. Also small matrix $\mathbf{K}_{\mathrm{II}}, \mathbf{K}_{\mathrm{II}}, \mathbf{K}_{\mathrm{II}} \quad \mathbf{K}_{\mathrm{III}}$ of stiffness one are the matrix corresponding to them.

We would like to consider transformational energy expressed the internal force of truss.

$$
U=\frac{1}{2} \sum_{i=1}^{n} \frac{N_{i}^{2}}{E F_{i}} l_{i}
$$

Here

$N_{i}$ - Internal force of $i$ prefab part, $N$

$A_{i}$ - Across-sectional area of $i$ th prefab part, $\mathrm{m}^{2}$

$n$ - Number of bars of making the truss

$F_{i}$ - Across-sectional area of bars of making the truss, $\mathrm{m}^{2}$

Because of all terms of this formula are positive values, if this value is minimum that the strength of internal force would be decreased unrelated to the tension or compression [6]. When it is used the basic equation of finite element method, the transformational energy formula (1) performed by internal force might be expressed as follows.

$$
U=\frac{1}{2} \mathbf{u}^{T} \mathbf{k} \mathbf{u}
$$

Here, $\mathbf{u}=\left\{\begin{array}{c}\mathbf{u}_{1} \\ \mathbf{u}_{\mathrm{II}}\end{array}\right\}, \quad \mathbf{K}=\left[\begin{array}{ll}\mathbf{K}_{\mathrm{II}} & \mathbf{K}_{\mathrm{III}} \\ \mathbf{K}_{\mathrm{III}} & \mathbf{K}_{\mathrm{III}}\end{array}\right]$

Because of the work performed by internal force equals to the work performed by external force, the formula as follows is satisfied.

$$
U=\frac{1}{2} \sum_{i=1}^{n} \frac{N_{i}^{2}}{E F_{i}} l_{i}=\frac{1}{2} \mathbf{u}^{T} \mathbf{k} \mathbf{u}=\frac{1}{2}\left(\mathbf{P}_{\mathrm{I}}^{T} \mathbf{u}_{1}+\mathbf{P}_{\mathrm{II}}^{T} \mathbf{u}_{\mathrm{II}}\right)
$$

From which, the problem to determine the additional external force could be formulated as follows.

$$
\left\{\begin{array}{c}
\mathbf{P}_{\mathrm{I}}^{T} \mathbf{u}_{\mathrm{I}}+\mathbf{P}_{\mathrm{II}}^{T} \mathbf{u}_{\mathrm{II}} \text { 炮 } \min \\
{\left[\begin{array}{ll}
\mathbf{K}_{\mathrm{II}} & \mathbf{K}_{\mathrm{III}} \\
\mathbf{K}_{\mathrm{II}} & \mathbf{K}_{\mathrm{III}}
\end{array}\right]\left\{\begin{array}{l}
\mathbf{u}_{\mathrm{I}} \\
\mathbf{u}_{\mathrm{II}}
\end{array}\right\}=\left\{\begin{array}{l}
\mathbf{P}_{\mathrm{I}} \\
\mathbf{P}_{\mathrm{II}}
\end{array}\right\}}
\end{array}\right.
$$


Therefore logical additional external force equals to the external force $\mathbf{P}_{\mathrm{II}}$ determined from the previous formula.

That is to say the problem is formulated as the conditional extreme value problem to determine the additional external force $\mathbf{P}_{\mathrm{II}}$ that minimizes the total internal force of structure as satisfying the stiffness equation characterized the movement of truss

\section{Solution of the setted problem}

It could be solved the setted problem by Laglangian undetermined multiplier method.

Composing of Laglangian function, it is as follows.

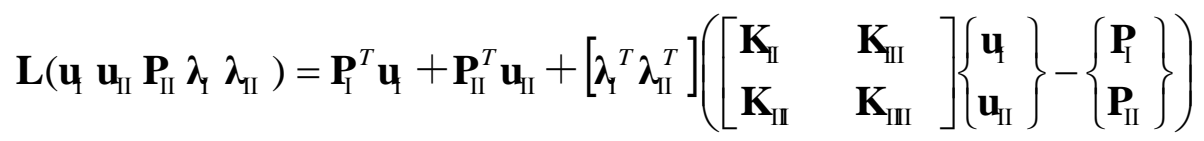

Here,

$\lambda_{1}, \lambda_{\mathbb{I}}$ - vetors of Laglangian undetermined multiplier

Applying the necessary condition of optimum.

$$
\left.\begin{array}{c}
\frac{\partial \mathbf{L}}{\partial \mathbf{u}_{\mathrm{I}}}=\mathbf{P}_{\mathrm{I}}+\lambda_{\mathrm{I}}{ }^{T} \mathbf{K}_{\mathrm{II}}+\boldsymbol{\lambda}_{\mathrm{II}}^{T} \mathbf{K}_{\mathrm{III}}=0 \\
\frac{\partial \mathbf{L}}{\partial \mathbf{u}_{\mathrm{II}}}=\mathbf{P}_{\mathrm{II}}+\lambda_{1}{ }^{T} \mathbf{K}_{\mathrm{III}}+\lambda_{\mathrm{II}}^{T} \mathbf{K}_{\mathrm{IIII}}=0
\end{array}\right\}
$$

By the condition $\frac{\partial \mathbf{L}}{\partial \mathbf{P}_{\mathrm{II}}}=0$, that is $\mathbf{u}_{\mathrm{II}}^{T}-\lambda_{\mathrm{II}}^{T}=0$ or

$$
\mathbf{u}_{\mathrm{II}}^{T}=\lambda_{\mathrm{II}}^{T}
$$

Arranging the formula (7) from the formula (8).

$$
\begin{gathered}
\mathbf{P}_{\mathrm{I}}+\mathbf{K}_{\mathrm{II}} \lambda_{\mathrm{I}}+\mathbf{K}_{\mathrm{III}} \mathbf{u}_{\mathrm{II}}=0 \\
\mathbf{P}_{\text {II }}+\mathbf{K}_{\text {II }} \lambda_{\mathrm{I}}+\mathbf{K}_{\text {II II }} \mathbf{u}_{\mathrm{II}}=0
\end{gathered}
$$

On the other hand, from the condition $\frac{\partial \mathbf{L}}{\partial \boldsymbol{\lambda}_{\mathrm{I}}^{T}}=0$ and $\frac{\partial \mathbf{L}}{\partial \boldsymbol{\lambda}_{\mathrm{II}}^{T}}=0$, limitational formula of the stiffness equation (1) is obtained. It is like as follows.

$$
\mathbf{K}_{\mathrm{II}} \quad \mathbf{u}_{\mathrm{I}}+\mathbf{K}_{\mathrm{III}} \quad \mathbf{u}_{\mathrm{II}}-\mathbf{P}_{\mathrm{I}}=0
$$




$$
\mathbf{K}_{\mathrm{III}} \mathbf{u}_{\mathrm{I}}+\mathbf{K}_{\mathrm{IIII}} \mathbf{u}_{\mathrm{II}}-\mathbf{P}_{\mathrm{II}}=0
$$

Therefore the setted problem is transformed to the problem that finds $\mathbf{u}_{1}, \mathbf{u}_{\mathrm{II}}, \boldsymbol{\lambda}_{\mathrm{I}} \mathbf{P}_{\mathrm{II}}$ from equation (9) and (10).

In orther to determine $\mathbf{P}_{\text {II }}$ I'll use the formula (9-a) and (10-b)

$$
\begin{aligned}
& \mathbf{K}_{\mathrm{II}} \quad \boldsymbol{\lambda}_{\mathrm{I}}+\mathbf{K}_{\mathrm{III}} \quad \mathbf{u}_{\mathrm{II}}=-\mathbf{P}_{\mathrm{I}} \\
& \mathbf{K}_{\mathrm{II}} \mathbf{u}_{\mathrm{I}}+\mathbf{K}_{\mathrm{III}} \quad \mathbf{u}_{\mathrm{II}}=\mathbf{P}_{\mathrm{I}}
\end{aligned}
$$

The formula (12) minus the formula (11) is as follows.

$$
\begin{array}{r}
\mathbf{K}_{\mathrm{I} \mathrm{I}}\left(\mathbf{u}-\lambda_{1}\right)=2 \mathbf{P}_{\mathrm{I}} \\
\text { Hence, } \boldsymbol{\lambda}_{1}=\mathbf{u}_{1}-2 \mathbf{K}_{\mathrm{II}}^{-1} \mathbf{P}_{\mathrm{I}}
\end{array}
$$

From the formula (9-b) and the formula (10-b),

$$
\begin{gathered}
\mathbf{K}_{\mathrm{III}} \lambda_{1}+\mathbf{K}_{\mathrm{III}} \mathbf{u}_{\mathrm{II}}=-\mathbf{P}_{\mathrm{II}} \\
\mathbf{K}_{\mathrm{III}} \mathbf{u}_{\mathrm{I}}+\mathbf{K}_{\mathrm{IIII}} \mathbf{u}_{\mathrm{II}}=\mathbf{P}_{\mathrm{II}}
\end{gathered}
$$

The formula (16) minus the formula (15) is as follows.

$$
\mathbf{K}_{\text {II }}\left(\mathbf{u}_{1}-\lambda_{1}\right)=2 \mathbf{P}_{\text {II }}
$$

Substituting the formula (14) for the formula (17)

$$
\mathbf{K}_{\text {III }}\left(\mathbf{u}_{1}-\mathbf{u}_{1}+2 \mathbf{K}_{\mathrm{II}}^{-1} \mathbf{P}\right)=2 \mathbf{P}_{\text {II }}
$$

Arranging the previous formula

$$
\mathbf{K}_{\mathrm{III}} \mathbf{K}_{\mathrm{II}}^{-1} \mathbf{P}=\mathbf{P}_{\mathrm{II}}
$$

The strength of logical additional external force is determined from the formula (19). As the formula (19), the additional external force $\mathbf{P}_{\text {II }}$ to minimize the internal force appeared in the truss structure that the external force $\mathbf{P}_{\mathrm{I}}$ is reacted, it is determined by the size of joint displacement appeared from the external force $\mathbf{P}_{\mathrm{I}}$ and the stiffness strength of the truss that is combined with the joint activated additional load. 
For example, on the roof truss structure like as figure 2, it is determined the additional external force $\mathbf{P}_{\text {II }}$ from the formula (19).

Here we assumed that $\mathbf{P}_{\mathrm{II}}=\left\{P_{C} P_{D}\right\}^{T}$ is to $P_{C}=P_{D}$.

Composing the stiffness matrix to given values, we can obtain $\mathbf{P}_{\mathrm{II}}$.

$$
\mathbf{P}_{\mathrm{II}}=\left\{P_{C} P_{D}\right\}^{T}=\{348348\}^{T} \mathrm{kN}
$$

4 The transformational process of internal force in the reinforcement of steel truss by activating the additional external force

The strength and place to activate the additional external force are determined by the operational situation of bars to reinforce and the reinforcement effects after that. While the additional external force is activated, the internal force of truss would be changed each time; before to reinforce, on reinforcing and after to reinforce [7].

Here for convenient, the additional external force $P_{C}, P_{D}$ are expressed as $P_{x i}$.

The first state (before to reinforce); it is the state that the external force (operational load) is activated to original truss system (Figure 2). If the load activated to one joint of truss is $\mathrm{P}_{\mathrm{i}}$, the total sum of external forces is $\sum \mathrm{P}_{\mathrm{i}}$.

The internal force that appeared in the truss bars is expressed as $\mathrm{N}_{\mathrm{p} 1 \mathrm{i}}$.

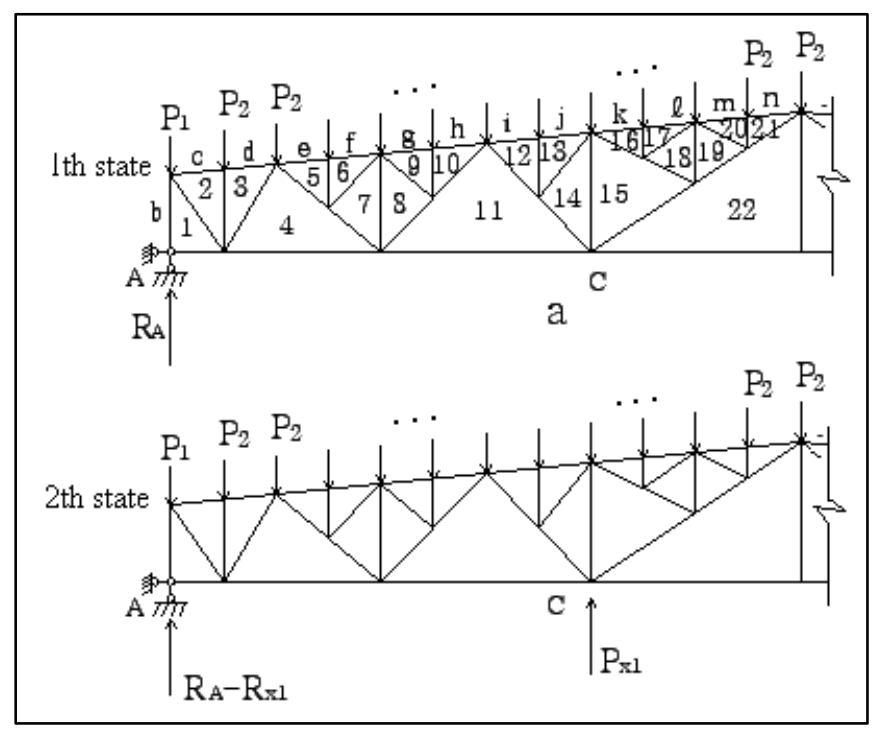

Figure 2. Diagram for calculating the strength of internal force by activating of the additional external force. 


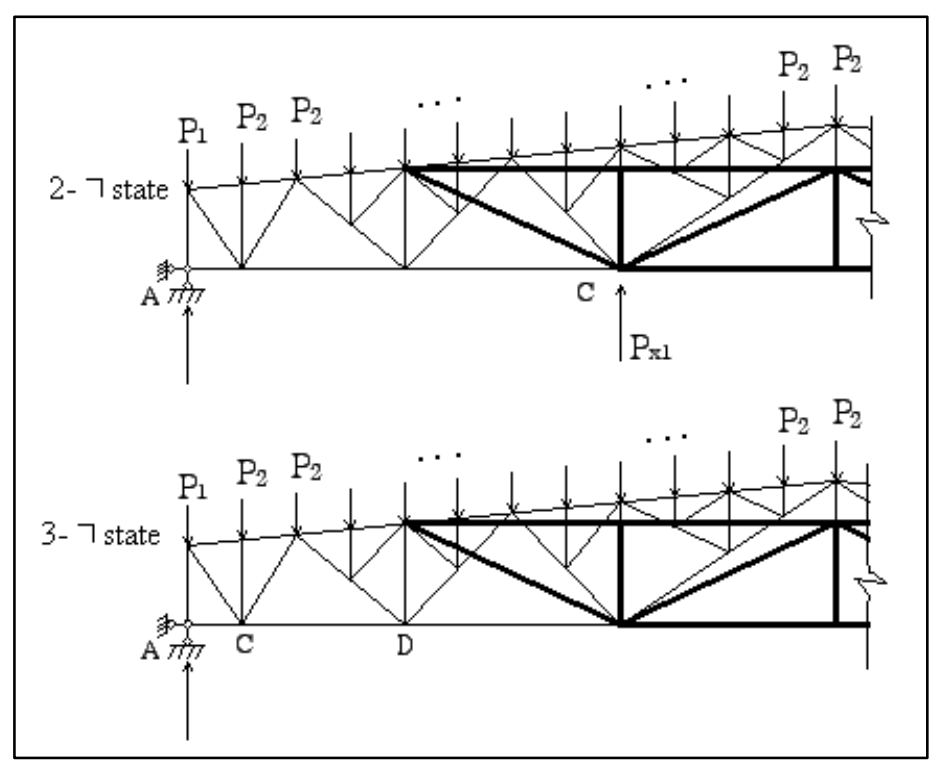

Figure 3. Diagram for calculating the strength of internal force by activating of the additional external force while the steel trusses are reinforced.

The second state; it is the atate that the opposite directional additional external force to the operational external force is activated.

Then the total external force activating to the truss system is as follows.

$$
\sum \mathrm{P}_{2 \mathrm{i}}=\sum \mathrm{P}_{\mathrm{i}}-\sum \mathrm{P}_{\mathrm{xi}}, \mathrm{N}
$$

Here

$\sum P_{i}$-the sum of the external forces actvating to the original truss system, $N$

$\sum \mathrm{P}_{\mathrm{xi}}$ - the sum of the external forces activated to the original truss system, $\mathrm{N}$

In this state the internal of truss bars could be expressed as the minus of the internal force of the original truss bars that are receiving the operational load and the internal force of truss bars that are receiving the additional external force.

$$
\left\{N_{P 2 i}\right\}=\left\{N_{P 1 i}\right\}-\left\{N_{P x i}\right\}, N
$$

Here

$\mathrm{N}_{\mathrm{P} 2 \mathrm{i}}$ - the internal force of the original truss bars in the second state, $\mathrm{N}$

$\mathrm{N}_{\mathrm{P} 1 \mathrm{i}}$ - the internal force of the original truss bars that are receiving operational load in the first state, $\mathrm{N}$

$\mathrm{N}_{\mathrm{Pxi}}$ - the internal force of the original truss bars that are receiving additional external force in the second state, $\mathrm{N}$

$2-\neg$ state $:$ it is the stage that the reinforcements are inserted as activating the additional external force. 
In the research for introduction in order to minimize damage and residual stress of the original truss bars while are reinforcing and after that [8], set out that only all reinforcments are combined on the junction plate of truss and the reinforcements are composed one of truss system (Figure 2- ᄀ).

It is called the reinforced truss in the original one to additional truss. At this moment the external and internal force and deflection state in the original truss system equal to the second state and the internal force in the reinforcements equals to zero. The third state; it is the state that the additional external force is disappeared after reinforcement. At this moment some of the disappeared additional external force acts to the original truss system and some acts to the additional truss system.

The internal force of the original truss system is as follows.

$$
\left\{N_{\mathrm{P} 3 i}\right\}=\left\{N_{\mathrm{P} 2 i}\right\}+\left\{N_{\mathrm{PS}, \mathrm{xi}}\right\}, N
$$

Here

$\left\{\mathrm{N}_{\mathrm{P} 3 \mathrm{i}}\right\} \quad$ - internal force in the original truss bars after reinforement, $\mathrm{N}$

$\left\{N_{\mathrm{PS}, \mathrm{xi}}\right\} \quad$ - internal force in the original truss bars appeared by the opposite directional external force that equals to strength and point of action of additional external force when additional force is removed after reinforcement, $\mathrm{N}$

Substituting the formular (21) to the formular (22), we can get a formular as follow.

$$
\left\{\mathbf{N}_{\mathrm{p} 3 \mathrm{i}}\right\}=\left\{\mathrm{N}_{\mathrm{P} 1 \mathrm{i}}\right\}-\left\{\mathrm{N}_{\mathrm{Pxi}}\right\}+\left\{\mathrm{N}_{\mathrm{PS}, \mathrm{xi}}\right\}, \mathrm{N}
$$

In this moment, internal force of additional truss system is as follow.

$$
\left\{N_{r, 3 i}\right\}=\left\{N_{p r, x i}\right\}, N
$$

Here

$$
\begin{aligned}
& \left\{N_{r, 3 i}\right\} \text { - internal force of additional truss system in the third state, } N \\
& \left\{N_{p_{r}, x i}\right\} \text { - internal force of additional truss system in case that additional external force is } \\
& \text { removed, } N
\end{aligned}
$$

If we perform reinforcement by the method of inserting the additional truss to the original steel truss and then remove the additional external force, the original truss system should become to inner statically indeterminate system [7].

In this case, if we assume that the opposite directional external force which equals to strength of additional external force is divided by its stiffness proportion to the original and additional truss.

Let us consider decreasing effect of internal force by reaction of additional external force in the truss like as figure 2. Truss span is $36 \mathrm{~m}$ and total load to the truss is $1200 \mathrm{kN}$. By using two 
hydraulic jacks with power of $500 \mathrm{~N}$, we activated the additional external force to C, D joint in the diagram of figure 2. We installed beams on the bogie frame of overhead crane and then installed the hydraulic jacks on it. As installing steel pipe column vertically on the jacks, the additional external force by hydraulic jacks was transfered to C, D joint of bottom chord of the truss (Figure 4). The strength of additional external force and decreasing of internal force in the truss were measured by tensiometer installed on the truss bars.

Before installing the hydraulic jacks, we must investigate that bearing capacity to additional external force is satisfied. Because of the diagram is giant structure, we considered left section by setting symmetry axis to criterion and expressed numers of bars in figure 2 .

Table 1. Internal force of top chord, kN

\begin{tabular}{|l|l|l|l|l|l|l|}
\hline \multicolumn{1}{|c|}{ Prefab part } & c-2 & d-3 & e-5 & f-6 & g-9 & h-10 \\
\hline Partition & -360 & -360 & -1077 & -1077 & -1077 & -1077 \\
\hline Operation load & -135 & -135 & -323 & -323 & -323 & -323 \\
\hline Ratio of internal decreasing, \% & 62.5 & 62.5 & 70 & 70 & 70 & 70 \\
\hline Partition Prefab part & $\mathrm{i}-12$ & $\mathrm{j}-13$ & $\mathrm{k}-16$ & $\mathrm{l}-17$ & $\mathrm{~m}-20$ & $\mathrm{n}-21$ \\
\hline Operation load & -1406 & -1406 & -1514 & -1514 & -1514 & -1514 \\
\hline Operation+addition load & -165 & -165 & -273 & -273 & -273 & -273 \\
\hline Ratio of internal decreasing, \% & 88.26 & 88.26 & 81.97 & 81.97 & 81.97 & 81.97 \\
\hline
\end{tabular}

Table 2. Internal force of bottom chord, kN

\begin{tabular}{|l|l|l|l|}
\hline \multicolumn{1}{|c|}{ Prefab part } & a-4 & $a-11$ & $a-22$ \\
\hline Partition & 644 & 1275 & 1317 \\
\hline Operation load & 224 & 259 & 267 \\
\hline Ratio of internal decreasing, \% & 65.22 & 79.68 & 79.22 \\
\hline
\end{tabular}

Table 3. Internal force of bottom chord, kN

\begin{tabular}{|c|c|c|c|c|c|c|c|}
\hline $\begin{array}{l}\text { Prefab part } \\
\text { Partition }\end{array}$ & $1-2$ & 3-4 & $4-5$ & $4-7$ & $8-11$ & $10-11$ & $11-12$ \\
\hline Operation load & 636 & -556 & 557 & 523 & -330 & -272 & 179 \\
\hline Operation+addition load & 239 & -174 & 127 & 93 & 53 & -74 & -136 \\
\hline Ratio of internal decreasing, $\%$ & 62.4 & 68.7 & 77.2 & 82.2 & 116 & 74.6 & 176 \\
\hline $\begin{array}{l}\text { Prefab part } \\
\text { Partition }\end{array}$ & $11-14$ & $15-22$ & $19-22$ & $21-22$ & 7-8 & $14-15$ & \\
\hline Operation load & 148 & 72 & 176 & 228 & -98 & -146 & \\
\hline Operation+addition load & -167 & -150 & -47 & 5 & -98 & -146 & \\
\hline Ratio of internal decreasing, $\%$ & 21.3 & 308 & 126.7 & 97.8 & 0 & 0 & \\
\hline
\end{tabular}

$※\langle-\rangle$ is compression member and others are tension member in the table.

As you can see in the table 1-3, the internal forces of truss bars are decreased more than $60 \%$ by additional external force. Applying this method, it must be noted that the bar which received 
tension in the structure before reinforcement has transfered into the compression bar. So, on these bars, we must check up the stable state on compression by additional external force and then must reinforce to them and react additional external force.

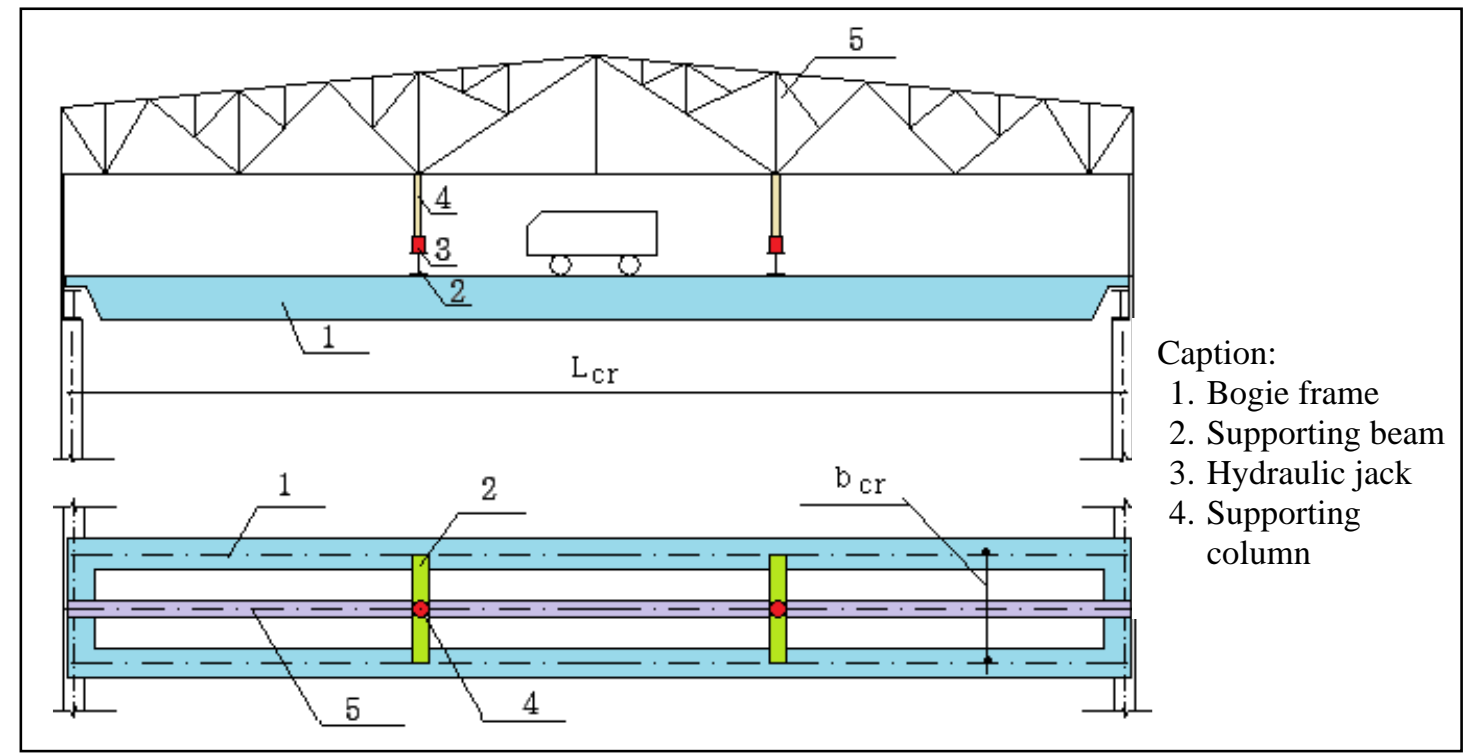

Figure 4. Diagram of movement installation of bogie frame to react additional external force

The method of reacting additional external force is as follows. Firstly, we must carefully investigate defacement, supporting state and the state of the roof plate or structure on the truss and remove probable accidental elements in reinforcement beforehand. Secondly, we must investigate deformation state of diagonal and vertical web member according to distribution and combination form of diagonal of the truss on the joints when additional external force is reacted.

Next we move and install the bogie frame of overhead crane in the situation of the truss for the purpose of reinforceing and install beams, hydraulic jacks and supporting column. And then we install the measuring instruments to measure characteristic of stress deformation.

After installation, as being operated the hydraulic jacks, we promote oil pressure till pressure delivers to the jacks. When oil pressure delivers to the jacks, we stop the supply of oil pressure and must confirm whether all instruments are placed in the initial state. After all instruments are initialized, rising oil pressure slowly, we react additional external force to the truss for the purpose of reinforcing. In this moment, we must react the additional external force by distributing into $1 / 10 \sim 1 / 15$ of total additional external force step by step; in every state, it is confirmed that system is placed in equilibrium state perfectly by using the measuring instruments, and then we must react additional external force of next state. When additional external force reaches to the purpose strength, we stand the hydraulic jacks to the stationary state and reinforce by keeping up the strength of additional external force. After reinforcement, we remove additional external force step by step slowly such as before. To the simple bent member such as beam, we can obtain the strength of additional external force by using following method. To beam, the strength of optical additional external force could be obtained 
simply under the condition that area of moment diagram by external force equals to area of one by additional external force.

Example of diagram, to determine the strength of additional external force in beam, is as figure 5.

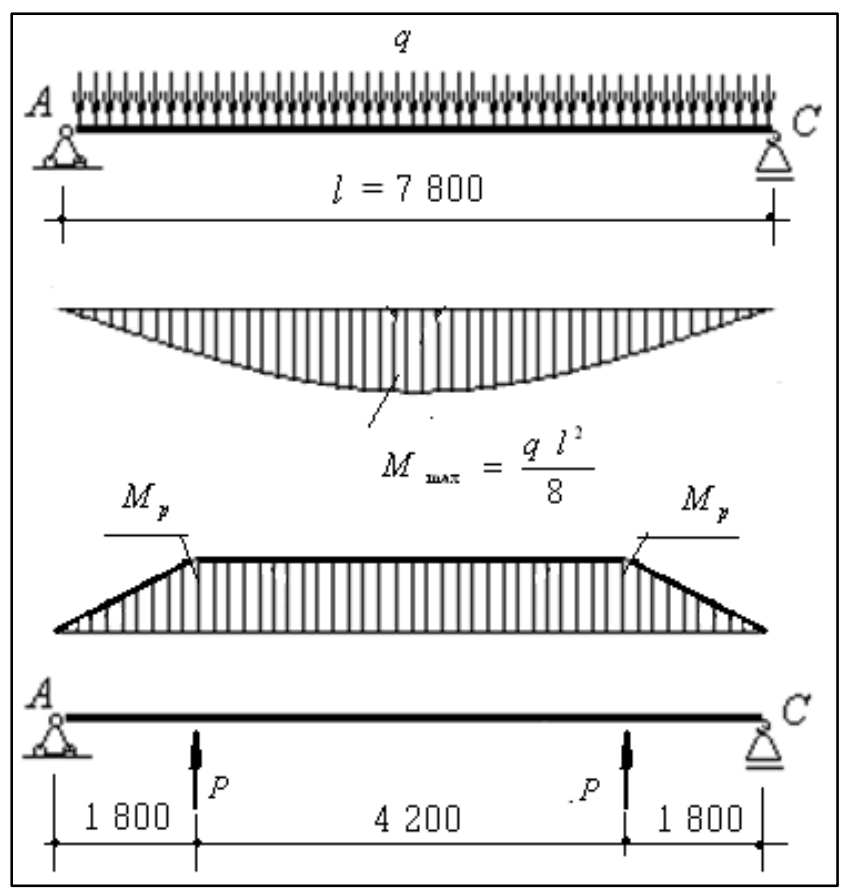

Figure 5. Diagram for determining the strength of additional external force in beam.

The span of beam is $3.8 \mathrm{~m}$ and dead load per unit length of beam that reacts to this interval is as follows.

Total load per unit length is $q=16.125(\mathrm{kN} / \mathrm{m})$.

Therefore maximum bending moment $M_{\max }$ in the middle of span is as follows.

$$
M_{\max }=\frac{q l^{2}}{8}=\frac{16.125 \times 7.8^{2}}{8}=122.6 \mathrm{kNm}
$$

When the additional external force is $\mathrm{P}$, bending moment $M_{p}$ in the place of $1.8 \mathrm{~m}$ from twoside bearing is as follows.

$$
M_{p}=P \times 1.8
$$

When the area of moment diagram by external force is $\omega$, it is as follows.

$$
\omega=\frac{2}{3} M_{\max } l=\frac{2}{3} \times 122.6 \times 7.8=637.5 \mathrm{kN} \mathrm{m}^{2}
$$

When the area of moment diagram by additional external force is $\omega_{p}$, it is as follow.

$$
\omega_{p}=2 \times \frac{1}{2} \times P \times 1.8 \times 1.8+P \times 1.8 \times 4.2=10.8 P \mathrm{~m}^{2}
$$


As the area of moment diagram by external force equals to one by additional external force, following formula is formed.

$$
\omega=\omega_{p}
$$

Therefore the strength of additional external force is as follows.

$$
P=637.5 / 10.8=59 \mathrm{kN}
$$

So, by using two hydraulic jacks with capacity of more than $50 \mathrm{kN}$, we react the additional external force and achieve the reinforcement and then remove the additional external force. In that case, we can achieve the purpose of reinforcement without damage to superstructure loading on the beam.

\section{Conclusion}

In this paper, in the case of reinforcing truss or beam, we have suggested the method to reinforce in state without subtract operation load. The contents solved in this research are as follows. Firstly, in case of reinforcing truss or beam, if internal force of structure equals or approximates to zero, we should rise the reinforcement effect maximum. In that case, if it is reacted the opposite directional force to the operational load on reinforcing structure, we can obtain effect such as subtracting the operational load. The strength of additional external force could be determined from the condition that the work that internal force of structure system carries out equals to the work that external force activated to this structure system carries out. To determine the strength of additional external force, we have formulated as the conditional extreme value problem that minimizes the total internal force of structure as satisfying stiffness equation characterized the movement of truss, and then had obtained its optimum solutions by applying Laglangian undetermined multiplier method. Secondly, in case of simple structure such as beam, we can determine the strength of additional external force from the condition that area of moment diagram by external force equals to area of one by additional external force.

\section{REFERENCES}

[1] Wang Guo Gu and Gang Jie Gous,.: Publishing Campany of qinghua university.

[2] Xi Ye Xiao, "Structural memoir of Japanese building sociaty," vol. 483, no. 157, 1997.

[3] A Formisano, A Massimilla, G Di Lorenzo, and R Landolfo, "Seismic retrofit of gravity load designed RC buildings using external steel concentric bracing systems," Engineering Failure Analysis , vol. 111, p. 104485, 2020.

[4] Herman Parung, Rudy Djamaluddin, Rita Irmawaty Pieter Lourens Frans, "The Effect Of Space Bar In The Truss Reinforcing System To The Flexural Capacity Of Reinforced Concrete Beams," International Journal of Civil Engineering and Technology (IJCIET), vol. 10, no. 04, pp. 754-462, 2019.

[5] Edward G Sutt and Timorthy A Reinhold, Method of reinforcing a building., 1998. 
[6] Anaelle Casanova, Ludovic Jason, and Luc Davenne, "Bond slip model for the simulation of reinforced concrete structures," Engineering Structures, vol. 39, pp. 66-78, 2012.

[7] Mu-Xuan Tao, Jian-Sheng Fan, and Jian-Guo Nie, "Seismic behavior of steel reinforced concrete column-steel truss beam hybrid joints," Engineering Structures, vol. 56, pp. 1557$1569,2013$.

[8] Marco Corradi, Adelaja Israel Osofero, and Antonio Borri, "Repair and reinforcement of historic timber structures with stainless steel," Metals, vol. 9, no. 1, p. 106, 2019. 